\title{
Risk of asthma in patients with primary Sjögren's syndrome: a retrospective cohort study
}

\author{
Te-Chun Shen 1,2,7, Hsuan-Ju Chen ${ }^{3}$, Chang-Ching Wei ${ }^{4}$, Chia-Hung Chen ${ }^{1,2}$, Chih-Yen Tu ${ }^{2}$, Te-Chun Hsia ${ }^{1,2}$, \\ Chuen-Ming Shih ${ }^{2}$, Wu-Huei Hsu' ${ }^{2}$, Fung-Chang Sung ${ }^{3,5,6^{*}+}$ and Da-Tian Bau ${ }^{1,7,8^{*}+}$
}

\begin{abstract}
Background: Sjögren's syndrome (SS) has been associated with bronchial hyperresponsiveness and asthma; however, no population-based cohort study has been performed. We evaluated the risk of asthma in patients with primary SS in a nationwide population.

Methods: We conducted a retrospective cohort study using data from the National Health Insurance Research Database in Taiwan. The primary SS group included 4725 adult patients diagnosed between 2000 and 2006. Each patient was frequency-matched with four people without SS by sex, age and year of diagnosis. The occurrence and hazard ratio (HR) of asthma was monitored by the end of 2011.

Results: The overall incidence density of asthma was 1.62-fold higher in the primary SS group than in the non-SS group (9.86 vs. 6.10 per 1000 person-years), with a multivariable Cox proportional hazards model measured adjusted HR of 1.38 [95\% confidence interval $(C l)=1.21-1.58]$. Stratified analyses by sex, age group, and presence of comorbidity revealed that asthma incidences were all higher in the primary SS group than in the non-SS group, and the relative HRs of asthma associated with primary SS were significant in all subgroups.

Conclusion: Patients with primary SS are associated with an increased risk of developing asthma. We should pay more attention to this group of individuals and provide them with appropriate support.
\end{abstract}

Keywords: Asthma, Sjögren's syndrome (SS), Autoimmunity, Retrospective cohort study

\section{Background}

Sjögren's syndrome (SS) is an autoimmune disease characterized by hypofunction of the lacrimal and salivary glands; however, the effects of SS are not limited to the eyes and mouth. SS is also featured by lymphocytic infiltration of exocrine glands. SS can present as an independent disorder itself (primary SS) or as a result of other autoimmune diseases, such as systemic lupus erythematosus (SLE), rheumatoid arthritis (RA), systemic sclerosis, or primary biliary cirrhosis (secondary SS) $[1,2]$. Approximately $90 \%$ of primary SS cases are

\footnotetext{
* Correspondence: fcsung1008@yahoo.com; artbau2@gmail.com ${ }^{\dagger}$ Equal contributors

${ }^{3}$ Management Office for Health Data, China Medical University Hospital, Taichung 404, Taiwan

${ }^{1}$ Graduate Institute of Clinical Medicine Science, College of Medicine, China Medical University, No. 91 Hsueh-Shih Road, Taichung 404, Taiwan Full list of author information is available at the end of the article
}

females and more prevalent in Caucasian women, with the mean onset age of $40-59$ [2]. With the incidence of $3.9-5.3$ per $100,000[3,4]$, the etiology of SS remains largely unknown. The combination of genetic, environmental, and hormonal factors may trigger the disorder [5]. Patients with SS may develop pulmonary manifestations such as airway disease and interstitial lung disease and follicular bronchiolitis is the most common histologic finding. Patients with significant pulmonary involvement could be at a 4-fold increased risk of death [6]. Therefore, recognition of these conditions is critical in caring for SS patients.

Asthma is a common respiratory disorder characterized by symptoms of wheezing, shortness of breath, chest tightness and cough. The occurrence, intensity, and frequency of these symptoms vary over time, and are associated with variable expiratory airflow, airway 
wall thickening, and mucus development [7]. Adult- and childhood- onset asthma are quite different; the former is generally non-allergic with severer symptoms and rapid decline in pulmonary function [8]. Pollutants and irritants exposure, upper airway diseases, respiratory infections, female sex hormones, medications, obesity, and stressful life events have been associated with the adultonset asthma [9].

Previous studies have described SS and the risk of respiratory disorders, including bronchial hyperresponsiveness (BHR) and asthma [10-16]. Fairfax et al. reported that 2 out of $17(11.8 \%)$ patients with SS were also comorbid with asthma [15]. In a large scale case-control study, Kang et al. reported that the prevalence of asthma was greater in the SS cases than in controls (5.1 vs. $3.4 \%$ ), with an adjusted odd ratio (OR) of 1.54 [95\% confidence interval $(\mathrm{CI})=1.22-1.93]$ [16]. However, the risk of asthma in patients with primary SS compared to the general population is largely unknown.

The National Health Insurance Research Database (NHIRD) of Taiwan is a nationwide database with cohort data including 23 million people. These reliable data have been used for various studies, including several on SS and asthma [17-20]. The hypothesis of this study is that primary SS may increase the likelihood of subsequent diagnosis of asthma. This study was to investigate the risk of asthma in patients with primary SS and compare it with the general population.

\section{Methods}

\section{Data sources}

The National Health Insurance (NHI) is a universal insurance program, which was reformed from 13 insurance systems in 1995. This insurance project has provided comprehensive coverage for $>99 \%$ of population since 1996. For the present study, we used the Registry of Catastrophic Illnesses Patient Database (RCIPD) and Longitudinal Health Insurance Database 2000 (LHID2000), which are parts of the NHIRD. The RCIPD contains health claims data for people with 30 major diseases, such as cancer, end-stage renal disease, chronic mental illness, and several autoimmune diseases, which are diseases requiring long-term care and are granted with co-pay exemption. The LHID2000 includes longitudinal data on medical claims for 1,000,000 individuals randomly sampled from the 2000 Registry of Beneficiaries. Both RCIPD and LHID2000 contain information on demographic data, clinical visits, prescription details, and diagnostic codes based on the International Classification of Diseases, Ninth revision, Clinical Modification (ICD-9-CM). All personal identifications in the data file were encrypted for privacy protection before being released for research; therefore, written informed consent from the participants involved was unavailable and unnecessary. This study was approved by the Research Ethic Committee of China Medical University and Hospital (CMUH-104-REC2-115).

\section{Study population}

From the data sets of RCIPD and LHID2000, we established two study cohorts for the population-based retrospective cohort study: primary SS cohort and non-SS cohort. Using the data file of RCIPD, adult patients with SS (ICD9-CM code 710.2) newly diagnosed during 2000-2006 were identified as the primary SS cohort. The date that the patient was approved with catastrophic illness certificate was designated as the index date. We excluded patients with secondary SS or a previous diagnosis of asthma (ICD-9-CM code 493). A secondary SS diagnosis was defined as a diagnosis of SS associated with SLE (ICD-9-CM code 710.0), RA (ICD-9-CM code 714), systemic sclerosis (ICD-9-CM code 710.1), or primary biliary cirrhosis (ICD-9-CM code 571.6) [17]. For each patient with primary SS, four insured individuals without SS or asthma were selected from LHID2000 as the non-SS cohort and were frequency-matched based on sex, age (every 5-years span), and year of the index date. The American-European Consensus Criteria was most commonly applied for the diagnosis of SS. According to the criteria, the diagnosis of SS can be met by fulfilling four out of six items, including ocular symptoms, oral symptoms, ocular signs, oral signs, evidence of histopathology, and presence of autoantibodies [21].

\section{Covariates and outcome}

Demographic factors including sex, age (age groups: $20-39,40-59$, and $\geq 60$ years), and medical histories (before the index date) of allergic rhinitis (ICD-9-CM code 477), chronic sinusitis (ICD-9-CM code 473), atopic dermatitis (ICD-9-CM code 691.8), chronic obstructive pulmonary disease (COPD; ICD-9-CM code 496), gastroesophageal reflux disease (GERD; ICD-9-CM codes 530.11 and 530.81), and obesity (ICD-9-CM code 278) were identified as comorbidities.

The primary outcome measure was asthma. Only patients with the diagnosis of asthma (ICD-9-CM code 493) at least twice within 1 year and prescription of treatment for asthma were identified as asthma cases to increase the validity and accuracy. The time of follow-up began with the index date and ended with a new diagnosis of asthma, death, withdrawal from the insurance program, or the end of follow-up on December 31, 2011.

\section{Statistical analysis}

Distributions of sex, age, and comorbidity were compared. The Pearson's Chi-square test and Student's $t$-test were used to determine the differences in categorical and continuous variables between the primary SS and 
non-SS groups. The incidence density of asthma was calculated by dividing the incident number of asthma by the follow-up person-years. We estimated the cumulative incidence of asthma by using the Kaplan-Meier method for the primary SS and non-SS groups and assessed their differences using the log-rank test. We used Cox proportional hazards regression to estimate the hazard ratios (HRs) and 95\% CIs of asthma to evaluate the independent effect of primary SS stratified by sex, age, and comorbidity. All statistical analyses were performed using SAS 9.4 (SAS System for Windows, SAS Institute, Cary, NC, USA). Results of comparisons using a two-tailed $p$-value of $<0.05$ were considered statistically significant.

\section{Results}

This study included 4725 patients with primary SS and 18900 individuals without SS that displayed similar distributions of sex and age (Table 1). The mean age of the primary SS group was $53.1(\mathrm{SD}=14.0)$ years, and $87.3 \%$ of patients were women. Prevalence rates of allergic rhinitis, chronic sinusitis, atopic dermatitis, COPD, and GERD were all greater in patients with SS than individuals without SS $(p<0.001$ for all).

Figure 1 shows that the cumulative incidence of asthma was $3.2 \%$ higher in the primary SS group than in the non-SS group $(9.0$ vs. $5.8 \%, p<0.001)$ after 12 year follow-up. During an average follow-up of 7.31 years, the incidence density of asthma was greater

Table 1 Demographic factors and comorbidities of study participants according to primary Sjögren's syndrome status

\begin{tabular}{|c|c|c|c|c|c|}
\hline \multirow[b]{2}{*}{ Variable } & \multicolumn{2}{|c|}{$\begin{array}{l}\text { Non-SS } \\
(N=18900)\end{array}$} & \multicolumn{2}{|c|}{$\begin{array}{l}\text { Primary SS } \\
(N=4725)\end{array}$} & \multirow[b]{2}{*}{$p$-value } \\
\hline & $n$ & $\%$ & $n$ & $\%$ & \\
\hline Sex & & & & & $>0.99$ \\
\hline Women & 16508 & 87.3 & 4127 & 87.3 & \\
\hline Men & 2392 & 12.7 & 598 & 12.7 & \\
\hline Age, years & & & & & $>0.99$ \\
\hline $20-39$ & 3524 & 18.7 & 881 & 18.7 & \\
\hline $40-59$ & 9532 & 50.4 & 2383 & 50.4 & \\
\hline$\geq 60$ & 5844 & 30.9 & 1461 & 30.9 & \\
\hline Means (SD) & 52.8 & $(14.3)$ & 53.1 & $(14.0)$ & 0.20 \\
\hline \multicolumn{6}{|l|}{ Comorbidity } \\
\hline Allergic rhinitis & 1566 & 8.29 & 997 & 21.1 & $<0.001$ \\
\hline Chronic sinusitis & 281 & 1.49 & 262 & 5.54 & $<0.001$ \\
\hline Atopic dermatitis & 259 & 1.37 & 111 & 2.35 & $<0.001$ \\
\hline COPD & 221 & 1.17 & 132 & 2.79 & $<0.001$ \\
\hline GERD & 77 & 0.41 & 95 & 2.01 & $<0.001$ \\
\hline Obesity & 85 & 0.45 & 20 & 0.42 & 0.90 \\
\hline
\end{tabular}

COPD chronic obstructive pulmonary disease, GERD gastroesophageal reflux disease, SD standard deviation, SS Sjögren's syndrome

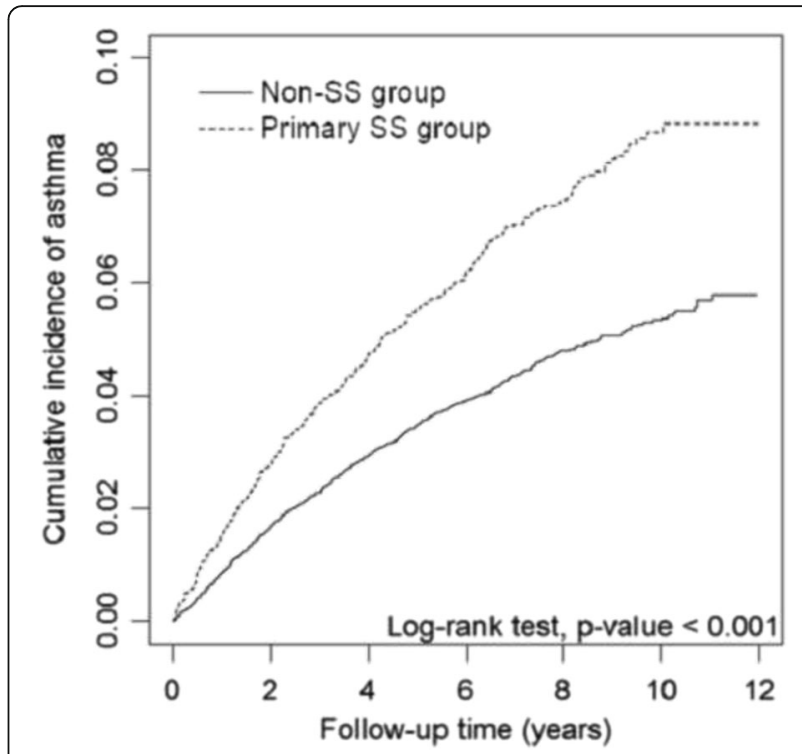

Fig. 1 Cumulative incidence of asthma in primary SS group and non-SS group

in the primary SS group than in the non-SS group, 9.86 vs. 6.10 per 1000 person-years (Table 2). The multivariable Cox method estimated adjusted HR of asthma was 1.38 (95\% CI $=1.21-1.58)$ for the primary SS group compared with non-SS group after controlling for sex, age, and comorbidities. The adjusted HRs were 1.41 in the $40-59$ years age group $(95 \% \mathrm{CI}=1.16-1.70)$ and 2.65 in the $\geq 60$ years age group $(95 \% \mathrm{CI}=2.19-3.22)$, compared with those aged less than 40 years. Compared with individuals free of COPD, those with COPD had an adjusted HR of 2.52 (95\% CI $=1.91-3.33)$ for developing asthma. On the other hand, adjusted HRs were $1.76(95 \% \mathrm{CI}=$ 1.51-2.06) for individuals with allergic rhinitis, 1.71 (95\% CI $=1.31-2.22)$ for individuals with chronic sinusitis, and $2.05(95 \% \mathrm{CI}=1.10-3.82)$ for individuals with obesity.

Table 3 shows incident asthma for both study cohorts by sex, age and comorbidity status. The primary SS group to the non-SS group adjusted HR was significant for women $(1.39,95 \% \mathrm{CI}=1.21-1.60)$. Age stratification demonstrated that incidence of asthma increased with age in both cohorts. The primary SS to non-SS group hazard ratio was greater for younger individuals. For individuals without comorbidity, those in the primary SS group had an adjusted HR of 1.47 (95\% CI $=1.25-1.72$ ) compared with those in the non-SS group.

\section{Discussion}

To the best of our knowledge, this is the first nationwide population-based retrospective cohort study to investigate the risk of asthma in patients with primary SS, comparing with general population. Results revealed that 
Table 2 Cox model measure hazard ratios and 95\% confidence intervals of asthma associated with primary Sjögren's syndrome and covariates

\begin{tabular}{|c|c|c|c|c|}
\hline \multirow[t]{2}{*}{ Variables } & \multirow[t]{2}{*}{ Events } & \multirow[t]{2}{*}{$\mathbb{I R}$} & \multicolumn{2}{|l|}{$\mathrm{HR}(95 \% \mathrm{Cl})$} \\
\hline & & & Univariate & Multivariate $^{a}$ \\
\hline \multicolumn{5}{|l|}{ Primary SS } \\
\hline No & 844 & 6.10 & 1.00 & 1.00 \\
\hline Yes & 337 & 9.86 & $1.62(1.42-1.83)^{* * *}$ & $1.38(1.21-1.58)^{* * *}$ \\
\hline \multicolumn{5}{|l|}{ Sex } \\
\hline Women & 1007 & 6.62 & 1.00 & 1.00 \\
\hline Men & 174 & 8.45 & $1.26(1.07-1.48)^{* *}$ & $0.90(0.76-1.06)$ \\
\hline \multicolumn{5}{|l|}{ Age, years } \\
\hline $20-39$ & 134 & 3.95 & 1.00 & 1.00 \\
\hline $40-59$ & 504 & 5.61 & $1.41(1.17-1.71)^{* * *}$ & $1.41(1.16-1.70)^{* * *}$ \\
\hline$\geq 60$ & 543 & 11.1 & $2.74(2.27-3.31)^{* * *}$ & $2.65(2.19-3.22)^{* *}$ \\
\hline \multicolumn{5}{|c|}{ Comorbidity } \\
\hline \multicolumn{5}{|c|}{ Allergic rhinitis } \\
\hline No & 952 & 6.13 & 1.00 & 1.00 \\
\hline Yes & 229 & 13.1 & $2.08(1.80-2.41)^{* * *}$ & $1.76(1.51-2.06)^{* * *}$ \\
\hline \multicolumn{5}{|c|}{ Chronic sinusitis } \\
\hline No & 1116 & 6.61 & 1.00 & 1.00 \\
\hline Yes & 65 & 17.5 & $2.58(2.01-3.32)^{* * *}$ & $1.71(1.31-2.22)^{* * *}$ \\
\hline \multicolumn{5}{|c|}{ Atopic dermatitis } \\
\hline No & 1153 & 6.77 & 1.00 & 1.00 \\
\hline Yes & 28 & 11.8 & $1.67(1.15-2.43)^{* *}$ & $1.39(0.95-2.02)$ \\
\hline \multicolumn{5}{|l|}{ COPD } \\
\hline No & 1123 & 6.58 & 1.00 & 1.00 \\
\hline Yes & 58 & 29.8 & $4.30(3.30-5.60)^{* * *}$ & $2.52(1.91-3.33)^{* * * *}$ \\
\hline \multicolumn{5}{|l|}{ GERD } \\
\hline No & 1167 & 6.80 & 1.00 & 1.00 \\
\hline Yes & 14 & 15.2 & $2.03(1.20-3.41)^{* *}$ & $1.28(0.75-2.17)$ \\
\hline \multicolumn{5}{|l|}{ Obesity } \\
\hline No & 1171 & 6.81 & 1.00 & 1.00 \\
\hline Yes & 10 & 14.1 & $2.02(1.09-3.77)^{*}$ & $2.05(1.10-3.82)^{*}$ \\
\hline
\end{tabular}

$\mathrm{Cl}$ confidence interval, COPD chronic obstructive pulmonary disease, GERD gastroesophageal reflux disease, $H R$ hazard ratio, $I R$ incidence density rate per 1000 person-years, SS Sjögren's syndrome

aModel was adjusted for sex, age and comorbidity in Cox proportional hazards regression

${ }^{*} p<0.05,{ }^{* *} p<0.01,{ }^{* * *} p<0.001$

patients with primary SS had an increased risk of asthma compared to those without SS. Stratified analyses by sex, age group, and presence of comorbidity also showed that the incidence rates of asthma were consistently higher in primary SS patients than in the comparison group, and the relative HRs of asthma associated with primary SS were significant for all subgroups. However, there were reduced significance levels in calculating adjusted HRs for some subgroups including males, those aged $>60$ years, and those with any comorbidity. The possible explanation for this may be that the case numbers were reduced in these subgroups, which in turn influenced the statistical power.

Asthma is a heterogeneous disease associated with different underlying disease processes and pathophysiologies. Recently, cluster analysis have classified asthma phenotypes by clusters of demographic, clinical, or pathophysiological characteristics [7]. A large number of studies have documented that adults with asthma may not associate with allergies, and the cellular profile of their airways may be neutrophilic, eosinophilic, or other types. These patients are classified as having non-allergic or adult-onset (late-onset) asthma, and they often respond less well to inhaled corticosteroid treatment [7]. Primary SS patients with BHR have characteristics similar to those with non-allergic or adult-onset asthma. Papiris et al. have reported that CD4 positive Tlymphocytes in the bronchial mucosa are increased outside of the bronchial glands in patients with SS, supporting the fact that SS involves extra-glandular tissues in the airways [22]. Amin et al. found that number of neutrophils, mast cells and $\mathrm{T}$ lymphocytes in the airways were higher in patients with primary SS than in healthy controls, while the number of eosinophils was similar in SS patients and controls [23]. Stalenheim et al. reported that inhaled budesonide was less effective for alleviating BHR in patients with SS [24]. In addition, Amin et al. have observed a lowered degree of epithelial integrity, but thicker tenascin and laminin layers in primary SS patients than in controls [23]. They concluded that structural changes in the airways relating to BHR were similar in SS patients and asthma patients [23]. Therefore, it is reasonable to include primary SS patients with BHR and related respiratory symptoms into a certain phenotype of asthma, which met the clinical diagnostic criteria.

Tobacco smoking has been considered as a potential confounding factor in the present study because the NHIRD does not contain data on personal smoking habits. One study has reported a weak association between cigarette smoking and the development of primary SS [25], while most studies reported no significant difference in smoking between primary SS patients and controls [26-28]. The case-control study on cardiovascular diseases even found significantly fewer smokers in the SS patient groups [29, 30]. Therefore, patients with SS may not have a significantly higher smoking rate than those without SS [18].

In the present study, we were able to observe a "real world" scenario using the claims data, in which primary SS, asthma, and comorbidities were directly diagnosed during medical consultations. In terms of the disease definition and patient registry, SS is categorized as a 
Table 3 Incidence density rates and hazard ratios of asthma according to primary Sjögren's syndrome status stratified by sex, age, and comorbidity

\begin{tabular}{|c|c|c|c|c|c|c|c|c|}
\hline \multirow[b]{3}{*}{ Variables } & \multicolumn{3}{|c|}{ No-SS group } & \multirow{2}{*}{\multicolumn{3}{|c|}{ Primary SS group }} & \multirow{2}{*}{\multicolumn{2}{|c|}{$\begin{array}{l}\text { Compared to the non-SS group } \\
\mathrm{HR}(95 \% \mathrm{Cl})\end{array}$}} \\
\hline & & & & & & & & \\
\hline & Events & Person-years & $\mathrm{IR}$ & Events & Person-years & $\mathrm{IR}$ & Relative & Adjusted $^{b}$ \\
\hline \multicolumn{9}{|l|}{ Sex } \\
\hline Women & 720 & 121936 & 5.90 & 287 & 30090 & 9.54 & $1.61(1.41-1.85)^{* * *}$ & $1.39(1.21-1.60)^{* * *}$ \\
\hline Men & 124 & 16497 & 7.52 & 50 & 4104 & 12.2 & $1.63(1.17-2.27)^{* *}$ & $1.31(0.92-1.86)$ \\
\hline \multicolumn{9}{|l|}{ Age, years } \\
\hline $20-39$ & 87 & 27166 & 3.20 & 47 & 6797 & 6.91 & $2.17(1.52-3.09)^{* * *}$ & $1.80(1.24-2.60)^{* *}$ \\
\hline $40-59$ & 351 & 72063 & 4.87 & 153 & 17771 & 8.61 & $1.77(1.46-2.13)^{* * *}$ & $1.54(1.26-1.87)^{* * *}$ \\
\hline$\geq 60$ & 406 & 39204 & 10.4 & 137 & 9626 & 14.2 & $1.37(1.13-1.67)^{* *}$ & $1.16(0.95-1.42)$ \\
\hline \multicolumn{9}{|c|}{ Comorbidity status $^{a}$} \\
\hline No & 658 & 123800 & 5.32 & 196 & 25269 & 7.76 & $1.47(1.25-1.72)^{* * *}$ & $1.47(1.25-1.72)^{* * *}$ \\
\hline Yes & 186 & 14633 & 12.7 & 141 & 8925 & 15.8 & $1.25(1.01-1.56)^{*}$ & $1.24(0.99-1.54)$ \\
\hline
\end{tabular}

Cl confidence interval, HR hazard ratio, IR incidence density rate per 1000 person-years, SS Sjögren's syndrome

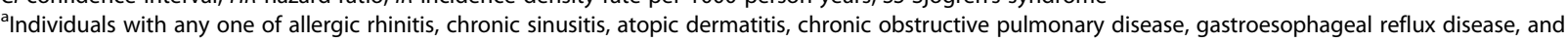
obesity were classified as the comorbidity group

${ }^{\mathrm{b}}$ Model was adjusted for sex, age and comorbidity in Cox proportional hazards regression

${ }^{*} p<0.05,{ }^{* *} p<0.01,{ }^{* * *} p<0.001$

"catastrophic illness" and patients diagnosed with SS are entitled to receive the "catastrophic illness certification" issued by the government. Experts specializing in the disease make critical evaluation of claims data, including serological, and/or pathological reports with reference to the American-European Consensus Criteria [21]. The diagnosis of asthma depends on a target history and requires comprehensive evidence of variable expiratory airflow limitations. We typically follow the Global Initiative for Asthma (GINA) guideline to arrive at an asthma diagnosis [7]. The insurance authority has established a committee to evaluate the claims data to prevent errors and violations. In addition, we only selected those diagnoses (asthma and comorbidities) that appeared at least twice within 1 year to increase the validity and accuracy of the diagnosis.

The universal coverage of the NHI project reduces barriers to health care access for all insured population, regardless of socioeconomic status [31]. In an earlier case-control study evaluating comorbidities for patients with primary SS, Kang et al. reported an odds ratio of 1.54 for asthma risk in primary SS patients, which is similar to our findings [16]. We suggest further evaluation of the differences in medications prescribed for asthma patients with primary SS compared to those without SS to better understand the current and common medical treatments for this population. In addition, future studies should evaluate the treatment outcomes such as acute exacerbations, admissions, intensive care, or mortality due to asthma in patients with primary SS.

The strength of this study comes from using the longitudinal population-based data to evaluate the asthma risk in primary SS patients. It is generally costly to conduct a population-based prospective cohort study. A retrospective cohort study based on insurance or registry data is an economically suitable alternative to evaluate this relationship, full compliance with the requirements of a follow-up study. However, several limitations of the study must be considered when interpreting the present findings. First, the NHIRD does not provide detailed information on potential confounding factors for this study, such as environmental factors, personal habits, diet preference, and family history. Since the crucial information is missing, it is difficult to judge whether we have used the most suitable comparison individuals. In addition, relevant clinical variables, such as image reports, histopathology results, serum laboratory data, pulmonary function tests, and symptom frequency in patients were also unavailable. We were unable to evaluate whether there is dose-response relationship between asthmatic risk and symptom frequency in SS patients.

\section{Conclusion}

Patients with primary SS are associated with a higher risk of developing asthma than those without SS. The association between primary SS and allergic or nonallergic asthma needs further investigation. In any case, we should pay more attention to patients with primary SS and provide them with appropriate support.

Acknowledgements

Not applicable. 


\section{Funding}

This study is supported in part by Taiwan Ministry of Health and Welfare Clinical Trial and Research Center of Excellence (MOHW105-TDU-B-212133019); Academia Sinica Taiwan Biobank, Stroke Biosignature Project (BM10501010037); NRPB Stroke Clinical Trial Consortium (MOST 105-2325-B039-003); Tseng-Lien Lin Foundation, Taichung, Taiwan; Taiwan Brain Disease Foundation, Taipei, Taiwan; Katsuzo and Kiyo Aoshima Memorial Funds, Japan; China Medical University Hospital; CMU under the Aim for Top University Plan of the Ministry of Education, Taiwan. The funders had no role in study design, data collection and analysis, decision to publish, or preparation of the manuscript. No additional external funding received for this study.

\section{Availability of data and material}

The authors do not own the data underlying the study. The study population's data were from Taiwan NHIRD (http://nhird.nhri.org.tw/) and are maintained by Taiwan National Health Research Institutes (TWNHRI) (http://www.nhri.org.tw/). The NHRI is a non-profit foundation established by the government. The data is freely available to interested researchers from the NHRI upon request.

\section{Authors' contributions}

ST carried out the conception and design, collection and assembly of data, data analysis and interpretation, and manuscript writing. WC, CC, and TC carried out the conception and design and collection and assembly of data. HT, SC, and HW carried out the administrative support and collection and assembly of data. $\mathrm{CH}, \mathrm{SF}$, and $\mathrm{BD}$ carried out the collection and assembly of data, data analysis and interpretation, and manuscript writing. All authors read and approved the final manuscript.

\section{Competing interests}

The authors declare that they have no competing interests.

\section{Consent for publication}

\section{Not applicable.}

\section{Ethics approval and consent to participate}

This study was approved by the Research Ethics Committee of China Medical University and Hospital, Taichung, Taiwan (CMUH-104-REC2-115). The NHRI of Taiwan manage the NHIRD and provide scrambled numbers for insured individuals to secure their privacy; therefore, written informed consent from the participants involved was unavailable and unnecessary. The committee approved the waiver.

\section{Author details}

${ }^{1}$ Graduate Institute of Clinical Medicine Science, College of Medicine, China Medical University, No. 91 Hsueh-Shih Road, Taichung 404, Taiwan. ${ }^{2}$ Division of Pulmonary and Critical Care Medicine, Department of Internal Medicine, China Medical University Hospital, No. 2 Yu-De Road, Taichung 404, Taiwan. ${ }^{3}$ Management Office for Health Data, China Medical University Hospital, Taichung 404, Taiwan. ${ }^{4}$ Children's Hospital, China Medical University Hospital, Taichung 404, Taiwan. ${ }^{5}$ Department of Health Services Administration, China Medical University, Taichung 404, Taiwan. ${ }^{6}$ College of Public Health, Kunming Medical University, No. 1168 Chunrongxi Road, Kunming 650500, YuanNan, China. ${ }^{7}$ Terry Fox Cancer Research Laboratory, Department of Medical Research, China Medical University Hospital, Taichung 404, Taiwan. ${ }^{8}$ Department of Bioinformatics and Medical Engineering, Asia University, No. 500 Lioufeng Road, Taichung 41354, Taiwan.

\section{Received: 26 July 2016 Accepted: 7 November 2016}

\section{Published online: 16 November 2016}

\section{References}

1. Rehman HU. Sjögren's syndrome. Yonsei Med J. 2003;44:947-54

2. Patel R, Shahane A. The epidemiology of Sjögren's syndrome. Clin Epidemiol. 2014;6:247-55.

3. Plesivcnik Novljan M, Rozman B, Hocevar A, Grmek M, Kveder T, Tomsic M. Incidence of primary Sjogren's syndrome in Slovenia. Ann Rheum Dis. 2004:63:874-6.

4. Alamanos Y, Tsifetaki N, Voulgari PV, Venetsanopoulou Al, Siozos C, Drosos AA. Epidemiology of primary Sjögren's syndrome in north-west Greece, 1982-2003. Rheumatol Oxf Engl. 2006:45:187-91.
5. Voulgarelis M, Tzioufas AG. Pathogenetic mechanisms in the initiation and perpetuation of Sjögren's syndrome. Nat Rev Rheumatol. 2010;6:529-37.

6. Stojan G, Baer AN, Danoff SK. Pulmonary manifestations of Sjögren's syndrome. Curr Allergy Asthma Rep. 2013;13:354-60.

7. Global strategy for asthma management and prevention. 2016 update. Global Initiative for Asthma. ( http://ginasthma.org )

8. Jeebhay MF, Ngajilo D, le Moual N. Risk factors for nonwork-related adultonset asthma and occupational asthma: a comparative review. Curr Opin Allergy Clin Immunol. 2014;14:84-94.

9. de Nijs SB, Venekamp LN, Bel EH. Adult-onset asthma: is it really different? Eur Respir Rev. 2013;22:44-52.

10. Potena A, La Corte R, Fabbri LM, Papi A, Trotta F, Ciaccia A. Increased bronchial responsiveness in primary and secondary Sjögren's syndrome. Eur Respir J. 1990;3:548-53.

11. Gudbjörnsson B, Hedenström H, Stålenheim G, Hällgren R. Bronchial hyperresponsiveness to methacholine in patients with primary Sjögren's syndrome. Ann Rheum Dis. 1991;50:36-40.

12. Ohmoto A, Kohno M, Matsuyama R. Bronchial hypersensitivity in Sjögren's syndrome. Ryumachi. 1994;34:10-5.

13. Lúdvíksdóttir D, Janson C, Björnsson E, Stålenheim G, Boman G, Hedenström $H$, et al. Different airway responsiveness profiles in atopic asthma, nonatopic asthma, and Sjögren's syndrome. Allergy. 2000;55:259-65.

14. Bellido-Casado J, Plaza V, Díaz C, Geli C, Domínguez J, Margarit G, et al. Bronchial inflammation, respiratory symptoms and lung function in primary Sjögren's syndrome. Arch Bronconeumol. 2011;47:330-4.

15. Fairfax AJ, Haslam PL, Pavia D, Sheahan NF, Bateman JR, Agnew JE, et al. Pulmonary disorders associated with Sjögren's syndrome. QJM. 1981; 50:279-95.

16. Kang JH, Lin HC. Comorbidities in patients with primary Sjogren's syndrome: a registry-based case-control study. J Rheumatol. 2010;37:1188-94.

17. Chung WS, Lin CL, Sung FC, Hsu WH, Chen YF, Kao CH. Increased risks of deep vein thrombosis and pulmonary embolism in Sjögren syndrome: a nationwide cohort study. J Rheumatol. 2014;41:909-15.

18. Shen TC, Wu BR, Chen HJ, Lin CL, Wei CC, Chen $\mathrm{CH}$, et al. Risk of chronic obstructive pulmonary disease in female adults with primary Sjögren's syndrome: a nationwide population-based cohort study. Medicine 2016;95:e3066.

19. Chung WS, Lin $\mathrm{CL}$, Chen YF, Ho FM, Hsu WH, Kao CH. Increased stroke risk among adult asthmatic patients. Eur J Clin Invest. 2014;44:1025-33.

20. Yeh JJ, Wang YC, Hsu WH, Kao CH. Incident asthma and mycoplasma pneumonia: a nationwide cohort study. J Allergy Clin Immunol. 2016;137:1017-23.

21. Vitali C, Bombardieri S, Jonsson R, Moutsopoulos HM, Alexander EL, Carsons SE, et al. Classification criteria for Sjögren's syndrome: a revised version of the European criteria proposed by the American-European Consensus Group. Ann Rheum Dis. 2002;61:554-8.

22. Papiris SA, Saetta M, Turato G, La Corte R, Trevisani L, Mapp CE, et al. CD4positive T-lymphocytes infiltrate the bronchial mucosa of patients with Sjögren's syndrome. Am J Respir Crit Care Med. 1997;156:637-41.

23. Amin K, Lúdvíksdóttir D, Janson C, Nettelbladt O, Gudbjörnsson B, Valtysdóttir $\mathrm{S}$, et al. Inflammation and structural changes in the airways of patients with primary Sjögren's syndrome. Respir Med. 2001;95:904-10.

24. Stålenheim G, Gudbjörnsson B. Anti-inflammatory drugs do not alleviate bronchial hyperreactivity in Sjögren's syndrome. Allergy. 1997;52:423-7.

25. Karabulut G, Kitapcioglu G, Inal V, Kalfa M, Yargucu F, Keser G, et al. Cigarette smoking in primary Sjogren's syndrome: positive association only with ANA positivity. Mod Rheumatol. 2011;21:602-7.

26. Gravani F, Papadaki I, Antypa E, Nezos A, Masselou K, loakeimidis D, et al. Subclinical atherosclerosis and impaired bone health in patients with primary Sjogren's syndrome: prevalence, clinical and laboratory associations. Arthritis Res Ther. 2015;17:99.

27. Schein OD, Hochberg MC, Muñoz B, Tielsch JM, Bandeen-Roche K, Provost $\mathrm{T}$, et al. Dry eye and dry mouth in the elderly: a population-based assessment. Arch Intern Med. 1999;159:1359-63.

28. Priori R, Medda E, Conti F, Cassarà EA, Sabbadini MG, Antonioli CM, et al. Risk factors for Sjögren's syndrome: a case-control study. Clin Exp Rheumatol. 2007:25:378-84.

29. Pérez-De-Lis M, Akasbi M, Sisó A, Diez-Cascon P, Brito-Zerón P, Diaz-Lagares

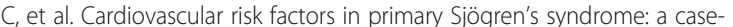
control study in 624 patients. Lupus. 2010;19:941-8. 
30. Bartoloni E, Baldini C, Schillaci G, Quartuccio L, Priori R, Carubbi F, et al. Cardiovascular disease risk burden in primary Sjögren's syndrome: results of a population-based multicentre cohort study. J Intern Med. 2015;278:185-92.

31. Hsing AW, loannidis JP. Nationwide population science: Lessons from the Taiwan National Health Insurance Research Database. JAMA Intern Med. 2015;175:1527-9

Submit your next manuscript to BioMed Central and we will help you at every step:

- We accept pre-submission inquiries

- Our selector tool helps you to find the most relevant journal

- We provide round the clock customer support

- Convenient online submission

- Thorough peer review

- Inclusion in PubMed and all major indexing services

- Maximum visibility for your research

Submit your manuscript at www.biomedcentral.com/submit 